CD38 and its role in oxyt ocin secret $i$ on and soci al behavi or

\begin{tabular}{|l|l|}
\hline 著者 & $\begin{array}{l}\text { H gashi da Har uhi ro, Yokoyama Shi ger u, K kuchi } \\
\text { M t sur u, Minesue Toshi o }\end{array}$ \\
\hline $\begin{array}{l}\text { j our nal or } \\
\text { publ i cat i on ti t l e }\end{array}$ & Hor mones and Behavi or \\
\hline vol une & 61 \\
\hline number & 3 \\
\hline page r ange & $351-358$ \\
\hline year & 2012- 03-01 \\
\hline URL & ht t p: //hdl . handl e. net /2297/30332 \\
\hline
\end{tabular}




\section{CD38 and its role in oxytocin secretion and social}

behavior

Haruhiro Higashida $^{1,2^{*}}$, Shigeru Yokoyama ${ }^{1,2}$, Mitsuru Kikuchi ${ }^{2}$ and Toshio Munesue ${ }^{2}$

${ }^{1}$ Department of Biophysical Genetics, Kanazawa University Graduate School of

Medicine, Kanazawa 920-8640, Japan,

${ }^{2}$ Osaka-Hamamatsu-Kanazawa Universities Joint Research Centers, Kanazawa

University Center for Child Mental Development, Kanazawa 920-8640, Japan,

*Corresponding author. Kanazawa University Graduate School of Medicine, 13-1

Kanazawa 920-8640, Japan,

E-mail address: haruhiro@med.kanazawa-u.ac.jp).

Key words: CD38, oxytocin, secretion, social behavior, SNP, autism. 


\section{Abstract}

Here, we review the functional roles of cyclic ADP-ribose and CD38, a transmembrane protein with ADP-ribosyl cyclase activity, in mouse social behavior via the regulation of oxytocin (OXT) release, an essential component of social cognition. Herein we describe data detailing the molecular mechanism of CD38-dependent OXT secretion in CD38 knockout mice. We also review studies that used OXT, OXT receptor (OXTR), or CD38 knockout mice. Additionally, we compare the behavioral impairments that occur in these knockout mice in relation to the OXT system and CD38. This review also examines autism spectrum disorder (ASD), which is characterized by social and communication impairments, in relation to defects in the OXT system. Two single nucleotide polymorphisms (SNPs) in the human CD38 gene are possible risk factors for ASD via inhibition of OXT function. Further analysis of CD38 in relation to the OXT system may provide a better understanding of the neuroendocrinological roles of OXT and CD38 in the hypothalamus and of the pathophysiology of ASD. 


\section{Contents}

1. Introduction

2. CD38 and cyclic ADP-ribose

3. $C D 38$ knockout mice

4. ADP-ribosyl cyclase activity

5. Human CD38

6. Human CD38 intronic rs3796863 SNP

7. Exonic rs1800561 SNP (R140W)

8. R140W mutation and oxytocin levels

9. Involvement of CD38 in the pathophysiology of ASD and additional prospectives

10. Conclusion 


\section{Introduction}

Oxytocin (OXT), a nonapeptide, is secreted into the brain by the dendrites or axons of the oxytocinergic neurons located in the paraventricular and supraoptic nuclei of the hypothalamus (Brownstein et al., 1980; Neuman et al., 1994 and 1996; Russell et al., 2003; Ludwig and Leng, 2006; Ross and Young, 2009). OXT regulates several complex social behaviors (Carter, 2003: Insel and Fernald, 2004; Donaldson and Young, 2008; Carter et al., 2009; Skuse and Gallagher, 2009; Ebstein et al., 2009; Insel, 2010; Higashida et al., 2007 and 2010). In humans, intranasal OXT may promote trust (Kosfeld et al., 2005), generosity (Zak et al., 2007), increased gaze to the eye region (Guastella et al., 2008a), inferring the emotions of others (Domes et al., 2007; Guastella et al., 2010; Kiss et al., 2011) and face recognition (Rimmele et al., 2009). Intranasal OXT has been proposed as a potential therapy to improve social deficits and has few, if any, negative side effects. (Yamasue et al., 2009; Ebstein et al., 2009: Munesue et al., 2010; MacDonald et al., 2011; Bartz et al., 2011). In rodents, OXT is highly involved in social interactions, social recognition, pair-bonding, and maternal behavior (Winslow 
and Insel, 2004; Insel and Fernald, 2004; Young and Wang, 2004; Young, 2007; Neumann, 2008; Donaldson and Young, 2008; Insel, 2010; Higashida et al., 2010). In addition, animal studies have shown that increased levels of OXT during the early postnatal period may affect behavior, and these effects may last into adulthood (Carter et al., 2009). Subcutaneous administration of low doses of OXT also facilitates social recognition (Popik et al., 1992). Two mouse models with either OXT or OXT receptor (OXTR) gene knockouts ( $\mathrm{Oxt}^{-1-}$ or $\mathrm{Oxtr}^{-{ }_{-}}$, respectively) show signs of profound social amnesia (Nishimori et al., 1996; Ferguson et al., 2000; Takayanagi et al., 2005; Crawley et al., 2007; Macbeth et al., 2010; Sala et al., 2011), which was rescued in the OXT knockout mice by the administration of OXT. These observations suggest that OXT plays an important role in social behavior via the stimulation of the OXTR during brain development and throughout the juvenile and adult life-stages (Ahern and Young, 2009; Carter et al., 2009; Insel, 2010).

In this review, we first discuss the roles of CD38 and ADP-ribosyl cyclase in the hypothalamus in the regulation of social behavior. This discussion is primarily based upon studies that showed how the reintroduction of CD38 into CD38 knockout mice 
affects the release of OXT. We further examine results obtained from studies in which

OXT and OXTR knockout mice were used to analyze the interaction between CD38 and

OXT. Finally, we focus on single nucleotide polymorphisms (SNPs) of the human

CD38 gene in relation to autism spectrum disorders (ASD).

\section{CD38 and cyclic ADP-ribose}

Recently, we reported that CD38, a type II transmembrane protein, controls

leukemia malignancy and is a marker of HIV infection in blood cells (Malavasi et al.,

2008). It is also required for normal social behavior in mice (Jin et al., 2007). CD38

possesses ADP-ribosyl cyclase activity (Lee, 2001; Higashida et al., 2001a and 2007;

Boittin et al., 2003; Guse, 2005) that produces cyclic ADP-ribose (cADPR) from

$\beta$-NAD ${ }^{+}$, also known as Vitamin B3, an abundant substrate in the brain (Denu, 2005).

cADPR is a potential intracellular second messenger and a cofactor for the movement of

$\mathrm{Ca}^{2+}$ through $\mathrm{Ca}^{2+}$-permeable channels $\left(\mathrm{Ca}^{2+}\right.$-induced $\mathrm{Ca}^{2+}$-release, CICR; Lee, 2001;

Higashida et al., 2001a and b; Endo, 2009) from ryanodine-sensitive $\mathrm{Ca}^{2+}$ pools, resulting in an increase in cytosolic free $\mathrm{Ca}^{2+}$ concentrations $\left(\left[\mathrm{Ca}^{2+}\right]_{\mathrm{i}}\right)$. Thus, it is 
possible that cellular events such as secretion or cell migration depend on the formation of cADPR. We have recently shown that CD38 is required, as shown by the decreased formation of cADPR and by CICR, for some social behaviors in mice via the regulation of OXT secretion from the hypothalamus and pituitary (Jin et al., 2007; Higashida et al., 2010; Salmina et al., 2010).

\section{CD38 knockout mice}

Mice lacking the $\mathrm{CD} 38$ gene $\left(C D 38^{-/}\right)$are viable, fertile, grow well, and gain weight (Kato et al., 1999; Liu et al., 2008) from the dam's milk during infancy and from solid food after weaning. $C D 38^{-/}$mice showed no deficits in lactation/milk ejection. Moreover, Nishimori et al., (1996) reported that mice lacking Oxt are viable and fertile. Although all offspring die shortly after birth because of the dam's inability to provide milk, postpartum injection of OXT into these Oxt-deficient dams restores milk ejection and rescues the offspring (Nishimori et al., 1996). Similarly, $\mathrm{Oxtr}^{-/}$mice are viable and have no obvious defects in fertility or sexual behavior. In addition, dams exhibit normal parturition, but display defects in lactation and maternal nurturing (Takayanagi et al., 
2005; Sala et al., 2011). These results indicate that, in the OXT/CD38/OXTR signaling pathway, OXT and OXTR are not essential for normal parturition but are required for milk ejection, while CD38 is not critically involved in reproduction.

$C D 38^{-/-}$male pups on postnatal day 7 had significantly higher levels of locomotor activity, compared to wild-type individuals, during the first $3 \mathrm{~min}$ after separation from the dam when they were examined individually in a grid-crossing test performed in an observation chamber (Liu et al., 2008). Both the $C D 38^{-/ /}$and $C D 38^{+/+}$ pups emitted ultrasonic vocalization (USV) upon isolation. The USV calls per 2-min session were less frequent (an average reduction of $38 \%$ ) in $C D 38^{-/-}$pups than in wild-type controls (Liu et al., 2008). The properties of the USVs were similar in both groups; the frequency was approximately $70 \mathrm{kHz}$ and the mean duration was approximately $60 \mathrm{~ms}$. These results are consistent with previous observations in $O x t^{-/}$ and Oxtr $^{-/}$mice (Nishimori et al., 1996; Takayanagi et al., 2005; Sala et al., 2011). Interestingly, the degree of disruption of infant behavior appeared to be mild in $C D 38^{-/-}$ mice compared with the two OXT-related knockout mouse strains (Higashida et al., 2010). To confirm this, the isolation-induced locomotor activity of four pups on the 
interacting plate (no physical contact but some interaction, e.g., USVs) was observed simultaneously for $18 \mathrm{~min}$. The $C D 38^{-/}$pups exhibited higher locomotor activity than the control pups (Liu et al., 2008). These observations suggest that $C D 38^{-/-}$pups retain the ability to interact socially with others.

Young male, adult mice investigate intruder females via olfaction in a stereotypic fashion and habituate after repeated encounters (Ferguson et al., 2000). $C D 38^{+/+}$males that experienced repeated pairings with the same conspecifics showed a significant decline in the time spent investigating the female upon subsequent presentations of the same animal. This was not due to a loss of interest, but to a retained memory of the paired female (Ferguson et al., 2000). The adult males did not need to further investigate the intruder females because they recognized the paired female as familiar. In contrast, $C D 38^{-/}$males showed sustained high levels of investigation at every encounter with the same female (Jin et al., 2007). This abnormality in social memory found in $C D 38^{--}$mice is due to the males' amnesia with respect to conspecifics. This amnesia resembles the memory deficit observed in $\mathrm{Oxt}^{-/-}$and $\mathrm{Oxtr}^{-/-}$mice (Ferguson et al., 2000; Takayanagi et al., 2005). 
In maternal behavior tests, wild-type dams retrieved five of their biological pups precisely and quickly (average latency, $43 \pm 3 \mathrm{~s}$ ) from a remote area of their home cages to a restricted area (Jin et al., 2007; Higashida et al., 2010), while $C D 38^{-/-}$dams took a significantly longer time to begin retrieval (average latency, $76 \pm 8 \mathrm{~s} ; \mathrm{p}<0.01$; Lopatina et al., 2011) and moved around, suggesting that their interest was drawn to things other than their pups. In addition, $C D 38^{-/}$dams often dropped the pups during retrieval, suggesting that they did not remember the way to the nest and resulting in the pups becoming scattered to multiple locations. $C D 38^{-/-}$dams fed the pups in their nest 30 min or more after the stressful perturbation. These results indicated clear (neglect-like) abnormalities in the maternal nurturing behavior of $C D 38^{-/}$postpartum mice under stressful conditions such as separation. However, this behavior improved considerably upon reproductive experience (Lopatina et al., 2011). The impairment of retrieval reported in $\mathrm{Oxtr}^{-/}$dams is similar to that observed in $\mathrm{CD} 38^{-/-}$females. In comparison with wild-type mice, $C D 38^{-/-}$mice have reduced OXT levels in the plasma and cerebrospinal fluid (CSF) (Jin et al., 2007) but elevated levels in the hypothalamus and pituitary tissues. These observations indicate that, although OXT is 
produced and packaged into the vesicles in the hypothalamic neurons and posterior pituitary nerve endings in $C D 38^{-/}$mice, it is not sufficiently released into the brain and bloodstream. The behavioral phenotype of $C D 38^{-/}$mice could be normalized by a single subcutaneous OXT injection because OXT is able to enter into the brain, probably through the blood-brain barrier (see Supplementary Fig. S7 of Jin et al., 2007). We used a genetic approach to re-express CD38 by infusing a virus carrying the human CD38 gene into the third ventricle of knockout mice. This procedure resulted in the normalization of the plasma and CSF OXT levels, thereby normalizing social memory (see Fig. 2 of Jin et al., 2007). This indicates that the mechanisms underlying social behavior require CD38-dependent OXT secretion (Fig. 1).

Interestingly, argine vasopressin (AVP) release is relatively insensitive to the CD38 null mutation. Because OXT and AVP neurons are relatively distinct from each other but are in the same SON and PVN areas of the hypothalamus, OXTnergic and AVPnergic neurons could be differentially controlled by CD38. It is not clear why CD38 mutation is insensitive to AVP neurons. In addition, given the role of cADPR in mobilizing $\mathrm{Ca}^{2+}$ from stores, additional neurotransmitter or peptide systems could be 
affected, because OXT and serotonin are colocalized in the brain, as has been shown in mice by Yoshida et al. (2009). The answer to these conundrums may lie in an inability to affect the depolarization-induced dopamine release in the striatum. The detection of dopamine by microdialysis was not impaired in $C D 38^{-/}$mice, demonstrating the specific involvement of CD38 in the OT secretion pathway in the hypothalamohypophysial neurons. However, we have no additional data on the CD38 regulation of other transmitters that contribute to social behavior,at this moment.

Surprisingly, the plasma OXT concentration in $C D 38^{-/-}$pups at 1 - 3 weeks of age does not decrease but is similar to that in $C D 38^{+/+}$mice of the same age (Liu et al., 2008). However, as expected, at 2 months of age (young adult) following weaning, there is a significantly lower plasma concentration of OXT in $C D 38^{-/}$mice than in $C D 38^{+/+}$mice. This decrease in OXT concentration following weaning occurs only in $C D 38^{-/-}$mice, suggesting that the switch from the juvenile to the adult stage is a critical period for regulating plasma OXT concentrations. Mammary milk was the sole food source for $C D 38^{-/}$pups in this study, as only milk curd was found in the stomachs of the offspring born to $C D 38^{-/}$females (Liu et al., 2008). This is considerably different 
from the findings in pups born to $O x t^{-/-}$and $O x t r^{-/-}$females (Nishimori et al., 1996; Furguson et al., 2000; Takayanagi et al., 2005; Crawley et al., 2007). OXT was abundant in the mammary gland tissue and milk of the lactating dams in the CD38 wild-type and knockout mice (Fig. 4 in Higashida et al., 2010). Plasma OXT appears to be controlled from different sources during the different life-stages. During the fetal stage, the fetus can obtain OXT from the placenta, which is linked to the mother, because OXT is transported to the fetus through the blood-placenta barrier (Malek et al., 1996). During the infant stage (suckling stage), the dams provide OXT to the pups from milk until weaning. Although the OXT in milk is degraded during digestion, because milk is the only food source for the pups during lactation, we speculate that suckling is the sole exogenous origin of plasma OXT during this time. During the adult stage (post-weaning stage), plasma OXT is derived entirely from endogenous synthesis and secretion. OXT levels remain high in wild-type mice during all developmental stages. In contrast, OXT levels decrease significantly after weaning in CD38 knockout mice (Liu et al., 2008; Fig. 3 in Higashida et al., 2010); this difference suggests a mechanism for why $C D 38^{-/-}$mice show different pathological phenotypes at each life-stage (Higashida 
et al., 2010).

\section{ADP-ribosyl cyclase activity}

In the central nervous system, the ADP-ribosyl cyclase activity corresponding to CD38 was detected at very high levels in the hypothalamus (see Supplementary Fig.

S11 of Jin et al., 2007). In the hypothalamus, the ADP-ribosyl cyclase activity in 1-week-old mice was $6 \%$ of that in 2 -month-old $C D 38^{+/+}$mice (Liu et al., 2008). Furthermore, ADP-ribosyl cyclase activity in $C D 38^{+/+}$mice was significantly higher than in age-matched knockout mice. $C D 38^{+/+}$mice showed significantly higher levels of ADP-ribosyl cyclase activity in the hypothalamus from the second week of life onward, and the difference in comparison with $C D 38^{-/-}$mice increased markedly (Higashida et al., 2010).

We recently showed that CD38 is involved in the $\mathrm{Ca}^{2+}$ concentration increase in a protein kinase C-dependent manner (Lopatina et al., 2010). In addition, heat, together with cADPR, contributes to the elevation of $\mathrm{Ca}^{2+}$ levels (Amina et al., 2010), likely due to the activation of $\mathrm{Ca}^{2+}$ permeability through transient receptor potential 
melastatin 2 (TRPM2) cation channels (Fig. 1). This has been shown in cultured NG108-15 neuroblastoma $\times$ glioma hybrid cells (Nirenberg et al., 1983). It is unknown if this occurs in the intact mammalian hypothalamus.

The role of ADP-ribosyl cyclase/CD38 in the regulation of OXT secretion through cADPR-mediated intracellular calcium signaling has been demonstrated in adult mice (Salmina et al., 2010). We observed both lower and similar levels of ADP-ribosyl cyclase activity in the hypothalamus and pituitary of 1-week-old $C D 38^{+/+}$ and $C D 38^{-/}$pups (Liu et al., 2008). Based on these observations, we speculate that the levels of ADP-ribosyl cyclase activity would also be relatively low at the fetal stage, suggesting that the maintenance of plasma OXT in the fetus and infants relies on exogenous sources such as the placenta or maternal milk. However, this hypothesis needs to be empirically tested. After weaning, the intrinsic activity of ADP-ribosyl cyclase in $C D 38$ knockout mice remains low, resulting in the relatively low levels of endogenous OXT release during development to the adult stage. This affects the social recognition behavior in the adult animals, as suggested by the long-term effects of OXT (Carter et al., 2009; Bridges, 2008). Considering these results in mice, we examined the 
role of $\mathrm{CD} 38$ in the human brain and in human social behavior relative to ASD.

\section{Human CD38}

CD38 mRNA expression in the human brain was examined by quantitative RT-PCR using commercially available human brain mRNA templates. The highest level of CD38 was found in the hypothalamus (Munesue et al., 2010). The human CD38 protein was detected (post-mortem) in the hypothalamus of Japanese and American human brains by immunoreactivity to the anti-human CD38 antibody. These results provide evidence that a similar role for CD38 in the regulation of OXT secretion and social behavior is possible in the human hypothalamus.

The human gene for CD38 is located on chromosome 4 at position p15 (Nakagawa et al., 1995; Nata et al., 1997; Malavasi et al., 2008) and consists of 8 exons, spanning a genomic stretch of $70.5 \mathrm{~kb}$ (Fig. 2). In the first set of cohort studies, these 8 exons and their flanking introns were screened for single nucleotide polymorphisms (SNPs) and mutations in 29 unrelated ASD subjects and in 201 non-clinical control subjects from the Kanazawa area in Japan (Figs. 2 - 4). The ASD patients fulfilled the 
diagnostic criteria for ASD found in the Diagnostic and Statistical Manual for Mental Disorders, Fourth edition (DSM-IV) and the CASK criteria for ASD, We detected 12 previously reported SNPs and 5 novel SNPs or mutations, with and without amino acid alterations, in ASD subjects and/or control subjects (Fig. 2).

\section{Human CD38 intronic rs3796863 SNP}

By examining CD38 SNPs from another subclass of ASD, the rs379863 (C > A) SNP in CD38 intron 7 showed a significant association with high-functioning autism (HFA) in individuals of American $(\mathrm{p}<0.005, \mathrm{n}=104)$ or non-Japanese $(\mathrm{p}=0.23$, $\mathrm{n}=188$ ) descent. The DNA samples examined in this study were obtained from the Autism Genetic Resource Exchange (Geschwind et al., 2001; Anitha et al., 2008) and the Hamamatsu Medical University Hospital (Munesue et al., 2010). This is one of few common variants which may contribute to the genetic susceptibility to HFA (Nakamura et al., 2008; Wermter et al., 2010). Based on the results of our SNP analysis and haplotype transmission disequilibrium test, the $\mathrm{C}$ allele of rs3796863 in CD38 may be a protective allele, and the A allele may be a risk allele in American HFA cases (Fig. 4 in 
Munesue et al., 2010; Fig. 5). Work by Lerer et al., (2010), showed that rs3796863 is significantly associated with low-functioning autism, but not necessarily HFA. Thus, this SNP may have a role in the pathogenesis of autism.

Because the allele frequency of SNP rs3796863 is 0.3, this variant is common. Very recently, common variants on chromosome 5p14.1, together with 6 meaningful variants between neural cadherins 10 and 9, have been reported to be associated with ASD (Wang et al., 2009). Since rs3796863 is an intronic SNP, the functional importance of this SNP remains to be determined. After examination of immortalized lymphoid cells from ASD subjects and their non-idiopathic parents, Lerer et al., (2010) suggested that this allele may contribute to the decreased expression of CD38 in ASD subjects. In addition, they suggested that retinoid could be a potential therapeutic agent to increase CD38 expression in ASD subjects (Fig. 5; Riebold et al., 2011; Ebstein, 2011).

There were significant variations in the 19 distributions of the ADI-R_C scores (restricted, repetitive, and stereotyped patterns of behavior) between the $\mathrm{C} / \mathrm{C}, \mathrm{C} / \mathrm{A}$, and A/A genotypes of this SNP in 252 trios and 104 HFA trios (see Fig. 3 of Munesue et al., 
2010). The second haploblock of CD38, which included rs3796863, showed a significant association with HFA. The association shown by the CT haplotype of the second haploblock remained significant by permutation.

\section{Exonic rs1800561 SNP (R140W)}

Among exon localized SNPs (Fig. 2), we detected the C4693T mutation in exon 3 (rs1800561) that leads to an arginine-to-tryptophan $(\mathrm{R}>\mathrm{W})$ substitution at amino acid $140(\mathrm{R} 140 \mathrm{~W})$. This mutation is very interesting because of the functional abnormality in R140W-substituted CD38. R140 is located in the flexible loop (amino acid residues 137-141) at the mid-point of the N- and C-terminal domains between two helical domains ( $\alpha \mathrm{a} 4$ and $\alpha \mathrm{a} 5$ ). It is the pivot point of the hinge region connecting two regions of the L-shaped molecule (Munesue et al., 2010). Therefore, the R140W mutation causes significant modifications and damage to the predicted protein structure in comparison with the human wild-type (R140) CD38 (see Fig. 7 of Munesue et al., 2010). As expected, the mutant R140W-CD38 showed one-third of the ADP-ribosyl cyclase activity of R140 CD38 when expressed in CHO cells (Yagui et al., 1998). In 
addition, social amnesia was not rescued by the local expression of human R140W-CD38, via a lentiviral infection, in the hypothalamus of CD38 knockout mice (Fig. 2 of Jin et al., 2007).

140R/W (C4693T) heterozygosity was found in 3 male subjects (2 autistic and 1 Asperger) of the 29 ASD subjects examined (23 males and 6 females; mean age, 22.8 \pm 7.6 years; prevalence, $10.3 \%$ ). We examined 315 healthy unscreened control subjects from the Kanazawa area. Two females and 1 male were positive for the heterozygous mutation, representing an allelic frequency of 0.0048 (Munesue et al., 2010). This frequency is 10.8 -fold lower than that $(0.052)$ in the ASD patient group from the same residential area $(\mathrm{p}<0.029)$.

We examined whether the R140W allele co-segregated with ASD and ASD-related traits in 3 proband families (Fig. 2). Twenty-five members from the 3 families of C-to-T heterozygous individuals were available for detailed clinical and genetic analyses. The 4693 C-to-T change was found in all proband fathers from each of the 3 families and in the brothers belonging to 2 families. The mutation appears to be an autosomal dominant trait. We identified 18 carriers in the 29 family members who 
agreed to be tested. In all cases, the mutation was heterozygous (allelic frequency $=$ 0.32). The mutant allele was transcribed in all of the subjects that were tested (Munesue et al., 2010).

The family members were clinically interviewed. The younger (upper family in the inset of Fig. 2) and older (lower family in the inset of Fig.2) brothers of the affected individuals showed clinical features conforming to ASD. Two fathers in their 50's and another father in his 70's were diagnosed with ASD traits. Most of the other adults over 50 years of age in these pedigrees had not been clinically diagnosed with ASD or any other psychiatric diseases and were well adapted to daily life.

We evaluated these individuals using the scores from the Japanese version of the Autism Spectrum Quotient (AQ), in which older subjects recalled behaviors from their 20 's. The AQ scores of 2 young male carriers in the families were relatively high (> 28), indicating that such carriers will manifest ASD (Fig. 3b and c). These clinical and self-describing evaluations are consistent with the hypothesis that the SNPs in the human CD38 gene may represent markers for risk alleles and that these observations warrant larger scale studies that have increased statistical power. 


\section{R140W mutation and oxytocin levels}

We obtained blood samples from family members of three C-to-T heterozygous probands to further study the connection between the human CD38 mutation and plasma OXT or AVP levels because we have previously shown that a null mutation of $C D 38$ resulted in the selective decrease of plasma OXT levels in mice (Jin et al., 2007). In addition, low levels of OXT have been reported in autistic children (Modahl et al., 1998). Plasma OXT levels in the carriers of the R140W mutation (161.3 $\pm 26.5 \mathrm{pg} / \mathrm{ml} ; \mathrm{n}=12)$ were lower than those in the relatives of non-carriers $(345.8 \pm$ $61.3 \mathrm{pg} / \mathrm{ml} ; \mathrm{n}=10 ; \mathrm{p}<0.01$ ) (Fig. 4a, c, e). The OXT levels of 3 probands and 2 brothers with the R140W SNP were compared with those of ASD subjects lacking the R140W mutation. The OXT plasma concentrations of the five R140W carriers $(79.2 \pm$ $16.6 \mathrm{pg} / \mathrm{ml} ; \mathrm{n}=5$; Munesue et al., 2010) were lower than those of ASD subjects lacking the mutation $(147.7 \pm 15.0 \mathrm{pg} / \mathrm{ml} ; \mathrm{p}<0.01 ; \mathrm{n}=26)$. Furthermore, the OXT levels of carrier ASD individuals were significantly lower than those in 101 control adults (198.2 $\pm 24.7 \mathrm{pg} / \mathrm{ml} ; \mathrm{p}<0.01, \mathrm{n}=101)$. 
Interestingly, the OXT levels in control carriers of the R140W allele were not lower when compared with healthy subjects (Fig. 3a). The reason for this is unclear. Furthermore, as expected, there was no difference in the AVP levels of CD38 mutation carriers and non-carriers within the same pedigrees (Fig. 4 b, d, f).

\section{Involvement of CD38 in the pathophysiology of ASD and additional prospectives}

Recent genetic and biological studies suggest that defects in OXT signaling confer vulnerability to ASD (Lim and Young, 2006). CD38 SNPs may provide a genetic basis for the cases of ASD that arise from the disruption of OXT signaling. The R140W SNP occurs relatively frequently in the Asian population (see Munesue et al., 2010), while we recently found only one heterozygous ASD patient with this SNP in a screen of AGRE samples from 551 white (non-Hispanic and non-Latino) subjects. These results suggest that the mutation is a risk factor of Asian ASD. The association study using Tag SNPs showed one SNP (rs3796863) in CD38 that positively correlated with American HFA and low functioning ASD in Israel. Therefore, it is possible that CD38 SNPs may provide a genetic basis for some ASDs, and therefore warrants further 
investigation.

Our preliminary studies suggest that a subgroup of ASD subjects with the R140W SNP and intelligence impairments may be effectively treated with OXT (Munesue et al., 2010), and these data lay the groundwork for evidence-based treatment of ASD by OXT administration. It is clear that a subgroup of ASD subjects with low plasma OXT levels could be a potential group that would benefit from OXT replacement therapy. However, low OXT levels are not only caused by CD38 SNPs but are also caused by other unknown reasons (Fig. 5). In addition, control carriers of the R140W allele did not have lower OXT levels (Fig. 3). It is unclear whether clinically unaffected carriers with this mutant allele may be influenced by compensatory factors for ASD. Altogether, these data support the existence of mechanisms of ASD pathogenesis other than CD38 SNPs. Further study is required to elucidate coordinating factors.

\section{Conclusion}


We have reviewed recent studies that have examined the neuroendocrinological

roles of cADPR and CD38 on the secretion of OXT in the mouse and human hypothalamus. There is increasing evidence for the critical role of CD38 in social behavior in mice and humans. Therefore, CD38 defects in the OXT signal system may be involved in the pathophysiology of ASD. However, many fundamental questions about the CD38/ OXT/ OXTR pathway and ASD remain unanswered. First, it is unknown whether CD38 activity is sensitive to environmental and social contexts. Recently, Kiss et al. (2011) reported that CD38 may contribute to the general secretion of OXT but that CD38 may not be related to OXT secretion upon psychological (empathy) stimulation. Second, it is unknown if the association of CD38 with ASD suggests a heightened susceptibility for immunological irregularity in individuals with ASD. Finally, the identities of additional molecules that interact with CD38 to regulate OXT secretion remain unknown.

\section{Acknowledgements}

This work was supported, in part, by grants from the following institutions: the Core 
Research for Evolutional Science and Technology (CREST); the Japan Science and Technology Agency in Tokyo, Japan; and the Ministry of Education, Culture, Sports, Science and Technology, Strategic Research Program for Brain Science in Tokyo, Japan. 


\section{References}

Ahern, T.H., Young, L.J., 2009. The impact of early life family structure on adult social attachment, alloparental behavior, and the neuropeptide systems regulating affiliative behaviors in the monogamous prairie vole (microtus ochrogaster). Front. Behav. Neurosci. 3, 17.

Amina, S., Hashii, M., Ma, W.J., Yokoyama, S., Lopatina, O., Liu, H.X., Islam, M.S., Higashida, H., 2010. Intracellular calcium elevation induced by extracellular application of cyclic-ADP-ribose or oxytocin is temperature-sensitive in rodent NG108-15 neuronal cells with or without exogenous expression of human oxytocin receptors. J. Neuroendocrinol. 22, 460-466.

Anitha, A., Nakamura, K., Yamada, K., Suda, S., Thanseem, I., Tsujii, M., Iwayama, Y., Hattori, E., Toyota, T., Miyachi, T., Iwata, Y., Suzuki, K., Matsuzaki, H., Kawai, M., Sekine, Y., Tsuchiya, K., Sugihara, G., Ouchi, Y., Sugiyama, T., Koizumi, K., Higashida, H., Takei, N., Yoshikawa, T., Mori, N., 2008. Genetic analyses of roundabout (ROBO) axon guidance receptors in autism. Am. J. Med. Genet. B Neuropsychiatr. Genet. 147B, 1019-1027.

Bartz, J.A., Zaki, J., Bolger, N., Ochsner, K.N., 2011. Social effects of oxytocin in humans: context and person matter. Trends Cogn. Sci. 15, 301-309.

Boittin, F.X., Dipp, M., Kinnear, N.P., Galione, A., and Evans, A.M., 2003. Vasodilation by the calcium-mobilizing messenger cyclic ADP-ribose. J. Biol. Chem. 278, 9602-9608. 
Born, J., Lange, T., Kern, W., McGregor, GP., Bickel, U., Fehm H.L., 2002. Sniffing neuropeptides: a transnasal approach to the human brain Nature Neurosci. 5, $514-516$

Bridges, R.S., 2008. Parenting and the brain: an overview. in Neurobiology of the Parental Brain. ed. Bridges, R.S. Academic Press, Elsevier, MA, pp xxix-xxxvi.

Brownstein, M.J., Russell, J.T., Gainer, H., 1980. Synthesis, transport, and release of posterior pituitary hormones. Science $207,373-378$.

Carter, C.S., 2003. Developmental consequences of oxytocin. Physiol. Behav. 79, 383-397.

Carter, C.S., Boone, E.M., Pournajafi-Nazarloo, H., Bales, K.L., 2009. Consequences of early experiences and exposure to oxytocin and vasopressin are sexually dimorphic. Dev. Neurosci. 31, 332-341.

Crawley, J.N., Chen, T., Puri, A., Washburn, R., Sullivan, T.L., Hill, J.M., Young, N.B., Nadler, J.J., Moy, S.S., Young, L.J., Caldwell, H.K., Young, W.S., 2007. Social approach behaviors in oxytocin knockout mice: comparison of two independent lines tested in different laboratory environments. Neuropeptides 41, 145-163.

Denu, J.M., 2005. Vitamin B3 and sirtuin function. Trends. Biochem. Sci. 30, 479-483.

Ditzen, B., Schaer, M., Gabriel, B., Bodenmann, G., Ehlert, U., Heinrichs, M., 2009. Intranasal oxytocin increases positive communication and reduces cortisol levels during couple conflict. Biol. Psychiatry 65, 728-731.

Domes, G., Heinrichs, M., Michel, A., Berger, C., Herpertz, S.C., 2007. Oxytocin improves "mind-reading" in humans. Biol. Psychiatry 61, 731-733. 
Donaldson, Z.R., Young, L.J., 2008. Oxytocin, vasopressin, and the neurogenetics of sociality. Science 322, 900-904.

Ebstein, R.P., Israel, S., Lerer, E., Uzefovsky, F., Shalev, I., Gritsenko, I., Riebold, M., Salomon, S., Yirmiya, N., 2009. Arginine vasopressin and oxytocin modulate human social behavior. Ann. N. Y. Acad. Sci. 1167, 87-102.

Ebstein, R.P., Mankuta, D., Yirmiya, N., Malavasi, F., 2011. Are retinoids potential therapeutic agents in disorders of social cognition including autism? FEBS Lett. $585,1529-1536$.

Endo, M., 2009. Calcium-induced calcium release in skeletal muscle. Physiol. Rev. 89, 1153-1176.

Esbensen, A.J., Greenberg, J.S., Seltzer, M.M., Aman, M.G., 2009. A longitudinal investigation of psychotropic and non-psychotropic medication use among adolescents and adults with autism spectrum disorders. J. Autism Dev. Disord, 39, 1339-1349.

Ferguson, J.N., Young, L.J., Hearn, E.F., Matzuk, M.M., Insel, T.R., Winslow, J.T., 2000. Social amnesia in mice lacking the oxytocin gene. Nature Genet. 25, 284-288.

Geschwind, D.H, Sowinski, J., Lord, C., Iversen, P., Shestack, J., Jones, P., Ducat, L., Spence, S.J.; AGRE Steering Committee., 2001. The autism genetic resource exchange: a resource for the study of autism and related neuropsychiatric conditions. Am. J. Hum. Genet. 69, 463-466.

Guastella, A.J., Einfeld, S.L., Gray, K.M., Rinehart, N.J., Tonge, B.J., Lambert, T.J., 
Hickie, I.B., 2010. Intranasal oxytocin improves emotion recognition for youth with autism spectrum disorders. Biol. Psychiatry. 67, 692-694.

Guastella, A.J., Mitchell, P.B., Dadds, M.R., 2008a. Oxytocin increases gaze to the eye region of human faces. Biol. Psychiatry 63, 3-5.

Guastella, A.J., Mitchell, P.B., Mathews, F., 2008b. Oxytocin enhances the encoding of positive social memories in humans. Biol. Psychiatry 64, 256-258.

Guse, A.H., 2005. Second messenger function and the structure-activity relationship of cyclic adenosine diphosphoribose (cADPR). FEBS J. 272, 4590-4597.

Higashida, H., Hashii, M., Yokoyama, S., Hoshi, N., Asai, K., Kato, T., 2001b. Cyclic ADP-ribose as a potential second messenger for neuronal $\mathrm{Ca} 2+$ signaling. J. Neurochem. 76, 321-331.

Higashida, H., Hashii, M., Yokoyama, S., Hoshi, N., Chen, X.L., Egorova, A., Noda, M., Zhang, J.S., 2001a. Cyclic ADP-ribose as a second messenger revisited from a new aspect of signal transduction from receptors to ADP-ribosyl cyclase. Pharmacol. Ther. 90, 283-296.

Higashida, H., Lopatina, O., Yoshihara, T., Pichugina, Y.A., Soumarokov, A.A., Munesue, T., Minabe, Y., Kikuchi, M., Ono, Y., Korshunova, N., Salmina, A.B., 2010. Oxytocin signal and social behaviour: comparison among adult and infant oxytocin, oxytocin receptor and CD38 gene knockout mice. J. Neuroendocrinol. 22, 373-379.

Higashida, H., Salmina, A.B., Olovyannikova, R.Y., Hashii, M., Yokoyama, S., Koizumi, K., Jin, D., Liu, H.X., Lopatina, O., Amina, S., Islam, M.S., Huang, J.J., 
Noda, M., 2007. Cyclic ADP-ribose as a universal calcium signal molecule in the nervous system. Neurochem. Int. 51, 192-199.

Hollander, E., Bartz „J., Chaplin, W., Phillips, A., Sumner, J., Soorya, L., Anagnostou, E., Wasserman, S., 2007. Oxytocin increases retention of social cognition in autism. Biol. Psychiatry. 61, 498-503.

Insel, T.R., 2010. The challenge of translation in social neuroscience: a review of oxytocin, vasopressin, and affiliative behavior. Neuron 65, 768-79.

Insel, T.R., Fernald, R.D., 2004. How the brain processes social information: searching for the social brain. Annu. Rev. Neurosci. 27, 697-722.

Jin, D., Liu, H.X., Hirai, H., Torashima, T., Nagai, T., Lopatina, O., Shnayder, N.A., Yamada, K., Noda, M., Seike, T., Fujita, K., Takasawa, S., Yokoyama, S., Koizumi, K., Shiraishi, Y., Tanaka, S., Hashii, M., Yoshihara, T., Higashida, K., Islam, M.S., Yamada, N., Hayashi, K., Noguchi, N., Kato, I., Okamoto, H., Matsushima, A., Salmina, A., Munesue, T., Shimizu, N., Mochida, S., Asano, M., Higashida, H., 2007. CD38 is critical for social behaviour by regulating oxytocin secretion. Nature 446, 41-45.

Kato, I., Yamamoto, Y., Fujimura, M., Noguchi, N., Takasawa, S., Okamoto, H., 1999. CD38 disruption impairs glucose-induced increases in cyclic ADP-ribose, $\left[\mathrm{Ca}^{2+}\right]_{\mathrm{i}}$, and insulin secretion. J. Biol. Chem. 274, 1869-1872.

King, B.H., Hollander, E., Sikich, L., McCracken, J.T., Scahill, L., Bregman, J.D., Donnelly, C.L., Anagnostou, E., Dukes, K., Sullivan, L., Hirtz, D., Wagner, A. Ritz, L., 2009. STAART Psychopharmacology Network: Lack of efficacy of 
citalopram in children with autism spectrum disorders and high levels of repetitive behavior: citalopram ineffective in children with autism. Arch. Gen. Psychiatry, 66, 583-590.

Kiss, I., Levy-Gigi, E., Kéri, S., 2011. CD 38 expression, attachment style and habituation of arousal in relation to trust-related oxytocin release. Biol. Psychol. 88, 223-226.

Kosfeld, M., Heinrichs, M., Zak, P.J., Fischbacher, U., Fehr, E., 2005. Oxytocin increases trust in humans. Nature 435, 673-676.

Kuehn, B.M., 2011. Scientists probe oxytocin therapy for social deficits in autism, schizophrenia. JAMA, 305, 659-661.

Lecavalier, L., 2006. Behavioral and emotional problems in young people with pervasive developmental disorders: relative prevalence, effects of subject characteristics, and empirical classification. J. Autism. Dev. Disord. 36, $1101-1114$.

Lee, H.C., 2001. Physiological functions of cyclic ADP-ribose and NAADP as calcium messengers. Ann. Rev. Pharmacol. Toxicol. 41, 317-345.

Lerer, E., Levi, S., Israel, S., Yaari, M., Nemanov, L., Mankuta, D., Nurit, Y., Ebstein, R.P., 2010. Low CD38 expression in lymphoblastoid cells and haplotypes are both associated with autism in a family-based study. Autism Res. 3, 293-302.

Lim, M.M., Young, L.J., 2006. Neuropeptidergic regulation of affiliative behavior and social bonding in animals. Horm. Behav. 50, 506-517.

Liu, H.X., Lopatina, O., Higashida, C., Tsuji, T., Kato, I., Takasawa, S., Okamoto, H., 
Yokoyama, S., Higashida, H., 2008. Locomotor activity, ultrasonic vocalization and oxytocin levels in infant CD38 knockout mice. Neurosci. Lett. 448, 67-70.

Lopatina, O., Inzhutova, A., Pichugina, Y.A., Okamoto, H., Salmina, A.B., Higashida, H., 2011. Reproductive experience affects parental retrieval behaviour associated with increased plasma oxytocin levels in wild-type and Cd38-knockout mice. J. Neuroendocrinol. doi: 10.1111.

Lopatina, O., Liu, H.X., Amina, S., Hashii, M., Higashida, H., 2010. Oxytocin-induced elevation of ADP-ribosyl cyclase activity, cyclic ADP-ribose or $\mathrm{Ca}^{2+}$ concentrations is involved in autoregulation of oxytocin secretion in the hypothalamus and posterior pituitary in male mice. Neuropharmacology. 58, $50-55$.

Ludwig, M., Leng, G., 2006. Dendritic peptide release and peptide-dependent behaviours. Nat. Rev. Neurosci. 7, 126-136.

Macbeth, A.H., Stepp, J.E., Lee, H.J., Young, W.S. 3rd, Caldwell, H.K., 2010. Normal maternal behavior, but increased pup mortality, in conditional oxytocin receptor knockout females. Behav. Neurosci. 124, 677-685.

MacDonald, E., Dadds, M.R., Brennan, J.L., Williams, K., Levy, F., Cauchi A.J., 2011. A review of safety, side-effects and subjective reactions to intranasal oxytocin in human research. Psychoneuroendocrinology in press.

MacDonald, K., MacDonald, T.M., 2010. The peptide that binds: a systematic review of oxytocin and its prosocial effects in humans. Harv. Rev. Psychiatry. 18, 1-21.

Malavasi, F., Deaglio, S., Funaro, A., Ferrero, E., Horenstein, A.L., Ortolan, E., Vaisitti, 
T., Aydin, S., 2008. Evolution and function of the ADP ribosyl cyclase/CD38 gene family in physiology and pathology. Physiol. Rev. 88, 841-886.

Malek, A., Blann, E., Mattison, D.R., 1996. Human placental transport of oxytocin. J. Matern. Fetal Med. 5, 245-255.

McCracken, J.T., McGough, J., Shah, B., Cronin, P., Hong, D., Aman, M.G., Arnold, L.E., Lindsay, R., Nash, P., Hollway, J., McDougle, C.J., Posey, D., Swiezy, N., Kohn, A., Scahil,1 L., Martin, A., Koenig, K., Volkmar, F., Carroll D., Lancor, A., Tierney, E., Ghuman, J., Gonzalez, N.M., Grados, M., Vitiello, B., Ritz, L., Davie,s M., Robinson, J. McMahon, D., 2002. Risperidone in children with autism and serious behavioral problems. N. Engl. J Med, 347, 314-321.

Modahl, C., Green, L., Fein, D., Morris, M., Waterhouse, L., Feinstein, C., Levin, H., 1998. Plasma oxytocin levels in autistic children. Biol. Psychiatry. 43, 270-277.

Munesue, T., Yokoyama, S., Nakamura, K., Anitha, A., Yamada, K., Hayashi, K., Asaka, T., Liu, H.X., Jin, D., Koizum,i K., Islam, M.S., Huang, J.J., Ma, W.J., Kim, U.H., Kim, S.J., Park, K., Kim, D., Kikuchi, M., Ono, Y., Nakatani, H., Suda, S., Miyachi, T., Hirai, H., Salmina, A., Pichugina, Y.A., Soumarokov, A.A., Takei, N., Mori, N., Tsujii, M., Sugiyama, T., Yagi, K., Yamagishi, M., Sasaki, T., Yamasue, H., Kato, N., Hashimoto, R., Taniike, M., Hayashi, Y., Hamada, J., Suzuki, S., Ooi, A., Noda, M., Kamiyama, Y., Kido, M.A., Lopatina, O., Hashii, M., Amina, S., Malavasi, F., Huang, E.J., Zhang, J., Shimizu, N., Yoshikawa, T., Matsushima, A., Minabe, Y., Higashida, H., 2010. Two genetic variants of CD38 in subjects with autism spectrum disorder and controls. Neurosci. Res. 67, 181-191. 
Nakagawara, K., Mori, M., Takasawa, S., Nata, K., Takamura, T., Berlova, A., Tohgo, A., Karasawa, T., Yonekura, H., Takeuchi, T., Okamoto, H., 1995. Assignment of CD38, the gene encoding human leukocyte antigen CD38 (ADP-ribosyl cyclase/cyclic ADP-ribose hydrolase), to chromosome 4p15. Cytogenet. Cell Genet. 69, 38-39.

Nakamura, K., Anitha, A., Yamada, K., Tsujii, M., Iwayama, Y., Hattori, E., Toyota, T., Suda, S., Takei, N., Iwata, Y., Suzuki, K., Matsuzaki, H., Kawai, M., Sekine, Y., Tsuchiya, K.J., Sugihara, G., Ouchi, Y., Sugiyama, T., Yoshikawa, T., Mori, N., 2008. Genetic and expression analyses reveal elevated expression of syntaxin $1 \mathrm{~A}$ (STX1A) in high functioning autism. Int. J. Neuropsychopharmacol. 11, 1073-1084.

Nata, K., Takamura, T., Karasawa, T., Kumagai, T., Hashioka, W., Tohgo, A., Yonekura, H., Takasawa, S., Nakamura, S., Okamoto, H., 1997. Human gene encoding CD38 (ADP-ribosyl cyclase/cyclic ADP-ribose hydrolase): organization, nucleotide sequence and alternative splicing. Gene 186, 285-292.

Neumann, I.D., 2008. Brain oxytocin: a key regulator of emotional and social behaviours in both females and males. J. Neuroendocrinol. 20, 858-865.

Neumann, I., Douglas, A.J., Pittman, Q.J., Russell, J.A., Landgraf, R., 1996. Oxytocin released within the supraoptic nucleus of the rat brain by positive feedback action is involved in parturition-related events. J. Neuroendocrinol. 8, 227-233.

Neumann, I., Koehler, E., Landgraf, R., Summy-Long, J., 1994. An oxytocin receptor antagonist infused into the supraoptic nucleus attenuates intranuclear and 
peripheral release of oxytocin during suckling in conscious rats. Endocrinol. 134, $141-148$

Nirenberg, M., Wilson, S., Higashida, H., Rotter, A., Krueger, K., Busis, N., Ray, R., Kenimer, J.G., Adler, M., 1983. Modulation of synapse formation by cyclic adenosine monophosphate. Science. 222, 794-799.

Nishimori, K., Young, L.J., Guo, Q., Wang, Z., Insel, T.R., Matzuk, M.M., 1996. Oxytocin is required for nursing but is not essential for parturition or reproductive behavior. Proc. Natl. Acad. Sci. U S A. 93, 11699-11704.

Popik, P., Vetulani, J., van Ree, J.M., 1992. Low doses of oxytocin facilitate social recognition in rats. Psychopharmacology (Berl). 106, 71-74.

Riebold, M., Mankuta, D., Lerer, E., Israel, S., Zhong, S., Nemanov, L., Monakhov, M.V., Levi, S., Yirmiya, N., Yaari, M., Malavasi, F., Ebstein, R.P., 2011. All-trans-Retinoic-Acid (ATRA) upregulates reduced CD38 transcription in lymphoblastoid cell lines from autism spectrum disorder. Mol, Med. Apr 25.

Rimmele, U., Hediger, K., Heinrichs, M., Klaver, P., 2009. Oxytocin makes a face in memory familiar. J. Neurosci. 29, 38-42.

Ross, H.E., Young, L.J., 2009. Oxytocin and the neural mechanisms regulating social cognition and affiliative behavior. Front. Neuroendocrinol. 30, 534-547.

Russell, J.A., Leng, G., Douglas, A.J., 2003. The magnocellularoxytocin system, the fount of maternity: adaptations inpregnancy. Front. Neuroendocrinol. 24, 27-61.

Sala, M., Braida, D., Lentini, D., Busnelli, M., Bulgheron,i E., Capurro, V., Finardi, A., 
Donzelli, A., Pattini, L., Rubino, T., Parolaro, D., Nishimori, K., Parenti, M., Chini, B., 2011. Pharmacologic rescue of impaired cognitive flexibility, social deficits, increased aggression, and seizure susceptibility in oxytocin receptor null mice: a neurobehavioral model of autism. Biol. Psychiatry 69, 875-882.

Salmina, A.B., Lopatina, O., Ekimova, M.V., Mikhutkina, S.V., Higashida, H., 2010. CD38/cyclic ADP-ribose system: a new player for oxytocin secretion and regulation of social behaviour. J. Neuroendocrinol. 22, 380-392.

Skuse, D.H., Gallagher, L., 20090. Dopaminergic-neuropeptide interactions in the social brain. Trends Cognitive Sci. 13, 27-35.

Takayanagi, Y., Yoshida, M., Bielsky, I.F., Ross, H.E., Kawamata, M., Onaka, T., Yanagisawa, T., Kimura, T., Matzuk, M.M., Young, L.J., Nishimori, K., 2005. Pervasive social deficits, but normal parturition, in oxytocin receptor-deficient mice. Proc. Natl. Acad. Sci. USA 102, 16096-16101.

Wang, K., Zhang, H., Ma, D., Bucan, M., Glessner, J.T., Abrahams, B.S., Salyakina, D., Imielinski, M., Bradfield, J.P., Sleiman, P.M., Kim, C.E., Hou, C., Frackelton, E., Chiavacci, R., Takahashi, N., Sakurai, T., Rappaport, E., Lajonchere, C.M., Munson, J., Estes, A., Korvatska, O., Piven, J., Sonnenblick, L.I., Alvarez Retuerto, A.I., Herman, E.I., Dong, H., Hutman, T., Sigman, M., Ozonoff, S., Klin, A., Owley, T., Sweeney, J.A., Brune, C.W., Cantor, R.M., Bernier, R., Gilbert, J.R., Cuccaro, M.L., McMahon, W.M., Miller, J., State, M.W., Wassink, T.H., Coon, H., Levy, S.E., Schultz, R.T., Nurnberger, J.I., Haines, J.L., Sutcliffe, J.S., Cook, E.H., Minshew, N.J., Buxbaum, J.D., Dawson, G., Grant, S.F., Geschwind, D.H., 
Pericak-Vance, M.A., Schellenberg, G.D., Hakonarson, H., 2009. Common genetic variants on 5p14.1 associate with autism spectrum disorders. Nature 459, 528-533.

Wermter, A.K., Kamp-Becker, I., Hesse, P., Schulte-Körne, G., Strauch, K., Remschmidt, H., 2010. Evidence for the involvement of genetic variation in the oxytocin receptor gene (OXTR) in the etiology of autistic disorders on high-functioning level. Am. J. Med. Genet. B Neuropsychiatr. Genet. 153B, 629-639.

Wing, L., Leekam, S.R., Libby, S.J., Gould, J., Larcombe, M., 2001. The diagnostic interview for social and communication disorders: background, inter-rater reliability and clinical use. J. Child Psychol, Psychiatry, 43, 307-325.

Winslow, J.T., Insel, T.R., 2004. Neuroendocrine basis of social recognition. Curr. Opin. Neurobiol. 14, 248-253.

Yagui, K., Shimada, F., Mimura, M., Hashimoto, N., Suzuki, Y., Tokuyama, Y., Nata, K., Tohgo, A., Ikehata, F., Takasawa, S., Okamoto, H., Makino, H., Saito, Y., Kanatsuka, A., 1998. A missense mutation in the CD38 gene, a novel factor for insulin secretion: association with Type II diabetes mellitus in Japanese subjects and evidence of abnormal function when expressed in vitro. Diabetologia 41, 1024-1028.

Yamasue, H., Kuwabara, H., Kawakubo, Y., Kasai, K., 2009. Oxytocin, sexually dimorphic features of the social brain, and autism. Psychiatry Clin. Neurosci. 63, 129-140.

Young, L.J., 2007. Regulating the social brain: a new role for CD38. Neuron. 54, 
$353-356$.

Young, L.J., Muns, S., Wang, Z., Insel, T.R., 1997. Changes in oxytocin receptor mRNA in rat brain during pregnancy and the effects of estrogen and interleukin- 6 . J. Neuroendocrinol. 9, 859-865.

Young, L.J., Wang, Z., 2004. The neurobiology of pair bonding. Nat. Neurosci. 7, 1048-1054.

Yoshida, M., Takayanagi, Y., Inoue K., Kimura. T., Young, L.J., Onaka, T., Nishimori, K., 2009. Evidence that oxytocin exerts anxiolytic effects via oxytocin receptor expressed in serotonergic neurons in mice. J. Neurosci. 29, 2259-2271.

Zak, P.J., Stanton, A.A., Ahmadi, S., 2007. Oxytocin increases generosity in humans. PLoS ONE 2 e1128. 


\section{Figure legends}

\section{Fig. 1.}

A schematic representation of oxytocin (OXT) release without depolarization, via the calcium (red dots) amplification signal of $\mathrm{Ca}^{2+}$-induced $\mathrm{Ca}^{2+}$-release (CICR) regulated by cyclic ADP-ribose (cADPR). CD38 and ADP-ribosyl cyclase activity in OXT-producing neurons in the hypothalamus (yellow) are regulated by protein kinase $\mathrm{C}$ (PKC) and can catalyze the conversion of cADPR from $\beta-\mathrm{NAD}^{+}$either intracellularly or extracellularly. cADPR, together with heat, can activate TRPM2 cation channels and facilitate the $\mathrm{Ca}^{2+}$ influx and $\mathrm{Ca}^{2+}$ release from ryanodine receptors (RyR). $\mathrm{Ca}^{2+}$ is released (green) from intracellular $\mathrm{Ca}^{2+}$ pools. OXT is released by the increased intracellular $\mathrm{Ca}^{2+}$ concentrations and is necessary for successful social interactions.

Fig. 2.

The genomic structure and single nucleotide polymorphisms of the human $C D 38$ gene located on chromosome 4 in the p15 region with 8 exons. Locations of SNPs in the introns (upper) and exons (lower). Numbering of the nucleotides starts at the A of the 
initial methionine (ATG) codon and refers to the GenBank accession number D84284.

Major allele/ minor allele. The amino acid substitutions at the codon numbers of each

SNP are shown. The number of control subjects (C) or ASD patients (P) with each exonic SNP, detected in the 57 family members of 3 ASD individuals, is shown. Inset shows the pedigrees of the 2 ASD individuals (arrows) carrying the R140W allele (red). Closed symbols represent individuals with the SNP. ASD patients in the lower family specified with a red arrow underwent nasal OXT treatment.

\section{Fig. 3.}

Plasma oxytocin (OXT) concentrations and autism-spectrum quotient (AQ) score. (a) A plot of the plasma OXT levels from 100 healthy control individuals with (red) or without (blue) the R140W allele. Note that the plasma OXT level in the R140W carriers of the non-idiopathic control group is not low. (b) AQ score in family members of the three family backgrounds with the R140W allele, together with typical ASD and control subjects. Assessment groups were: R140W: $\mathrm{n}=14$ family members with the mono-allelic R140W mutation; R140: $\mathrm{n}=7$ persons without the mutation in the families. 
The mean or standard error (SE) and standard deviation (SD) ranges of AQ scores are shown. Note that 5 individuals show an intermediate score above the control range but below the ASD score (28). The score of individuals with R140W is higher than those without (one-way ANOVA, $p<0.05$ ). (c) A plot of the AQ scores of each family member with or without the R140W SNP according to age. No significance was found between three generations ( $20<$ age $<40,40<$ age $<60$ and $60<$ age) by two-way ANOVA. The scores of the males are significantly higher than those of the females $(p<$ 0.05). Circles indicate females, and diamonds indicate males. (d) Plasma oxytocin levels of the ASD patient who was administered nasal OXT (a member of the family from the inset of Fig. 2) at the beginning of treatment (red circle) and healthy males (diamonds) are plotted as a function of age.

Fig. 4.

Plasma oxytocin and vasopressin levels in family members. Plasma concentrations of OXT (a) and AVP (b) levels in family members with (R140W; $\mathrm{n}=12$, red or orange bars) or without (R140; $\mathrm{n}=10$, green or blue bars) the heterozygous $\mathrm{R} 140 \mathrm{~W}$ allele. 
Mean \pm s.e.m. ${ }^{* *}, \mathrm{p}<0.01$ (one-way ANOVA). OXT (c) or AVP (d) levels in the three families according to age. OXT (e) or AVP (f) levels as a function of AQ scores. The red and orange symbols and the green and blue symbols indicate levels from persons with or without the R140W mutation, respectively. Circles denote females and diamonds or squares denote males.

\section{Fig. 5.}

Model of how single nucleotide polymorphisms (SNPs) lead to autism spectrum disorder (ASD) or not (non-ASD). rs3796863 and rs1800561 (R140W) SNPs may cause low levels of oxytocin (OXT) in the brain or plasma by lowering the expression or enzymatic activity of CD38. The low plasma OXT level may also be produced by other unknown causes. ASD may be triggered by additional strong risk factors and/or other weak protective factors. Additionally, protection from ASD may also be induced by other weak risk factors and/or strong protective factors, including female hormones such as OXT. Recently, retinoids (vitamin A analogs) have shown potential as treatments for ASD because all-trans retinoic acids can induce CD38 transcription and 
rescue low CD38 expressing lymphoid cells derived from ASD patients (Wbstein et al., 2011). For the rescue of low plasma or brain OXT levels in ASD patients, OXT replacement may be achieved by the nasal delivery of OXT. 


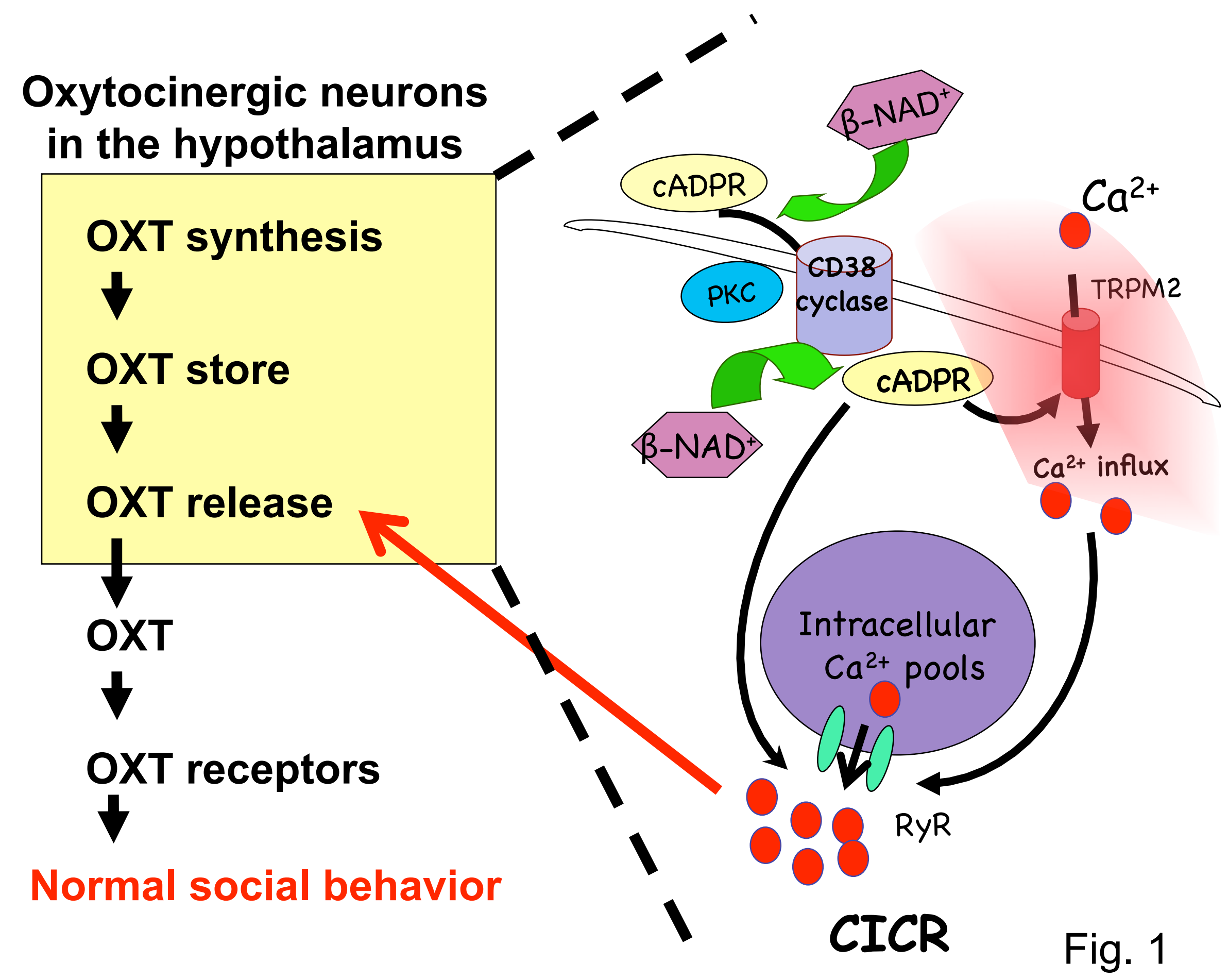




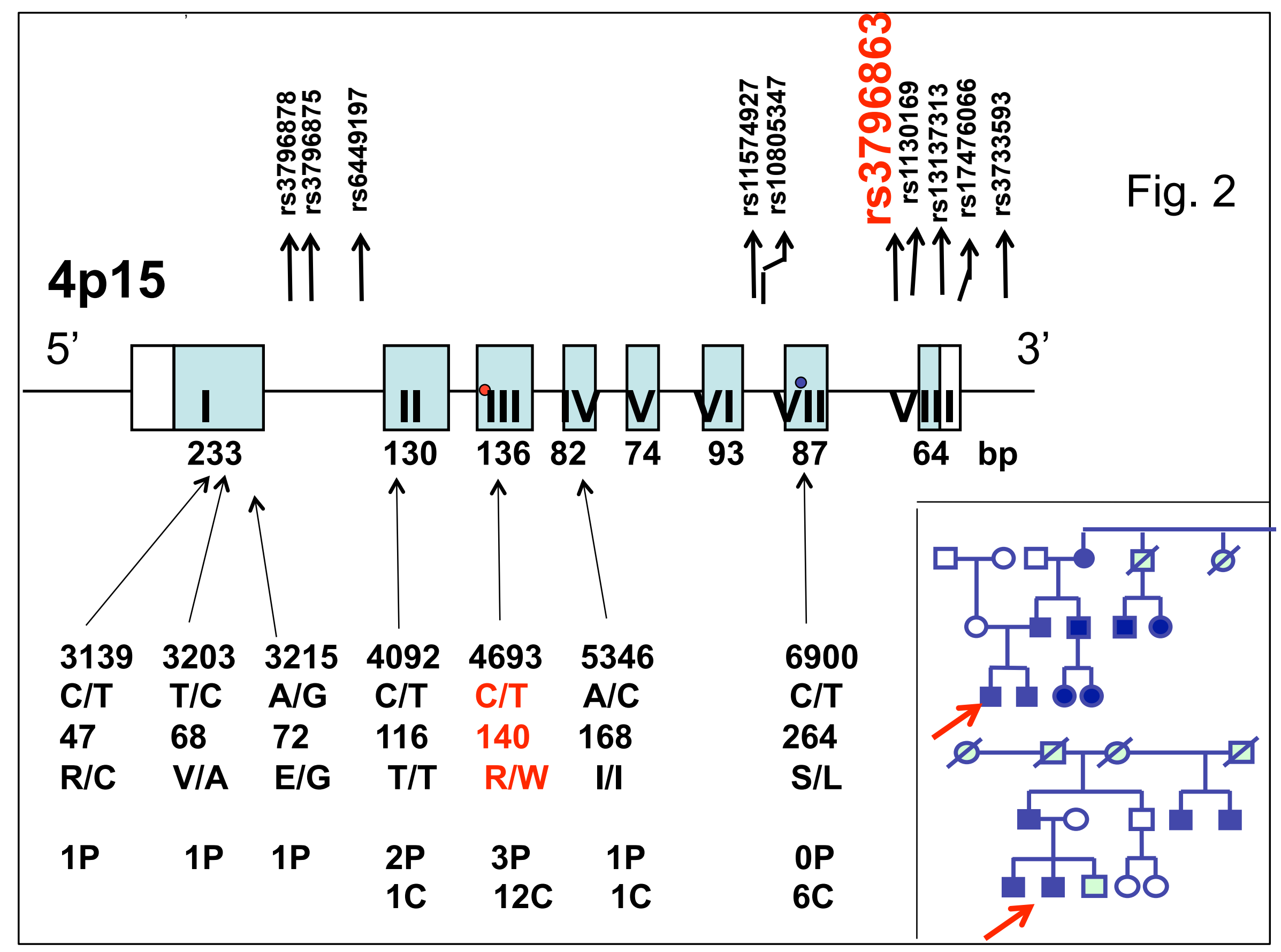


a

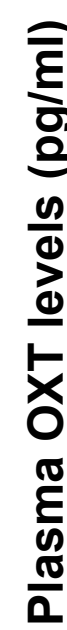
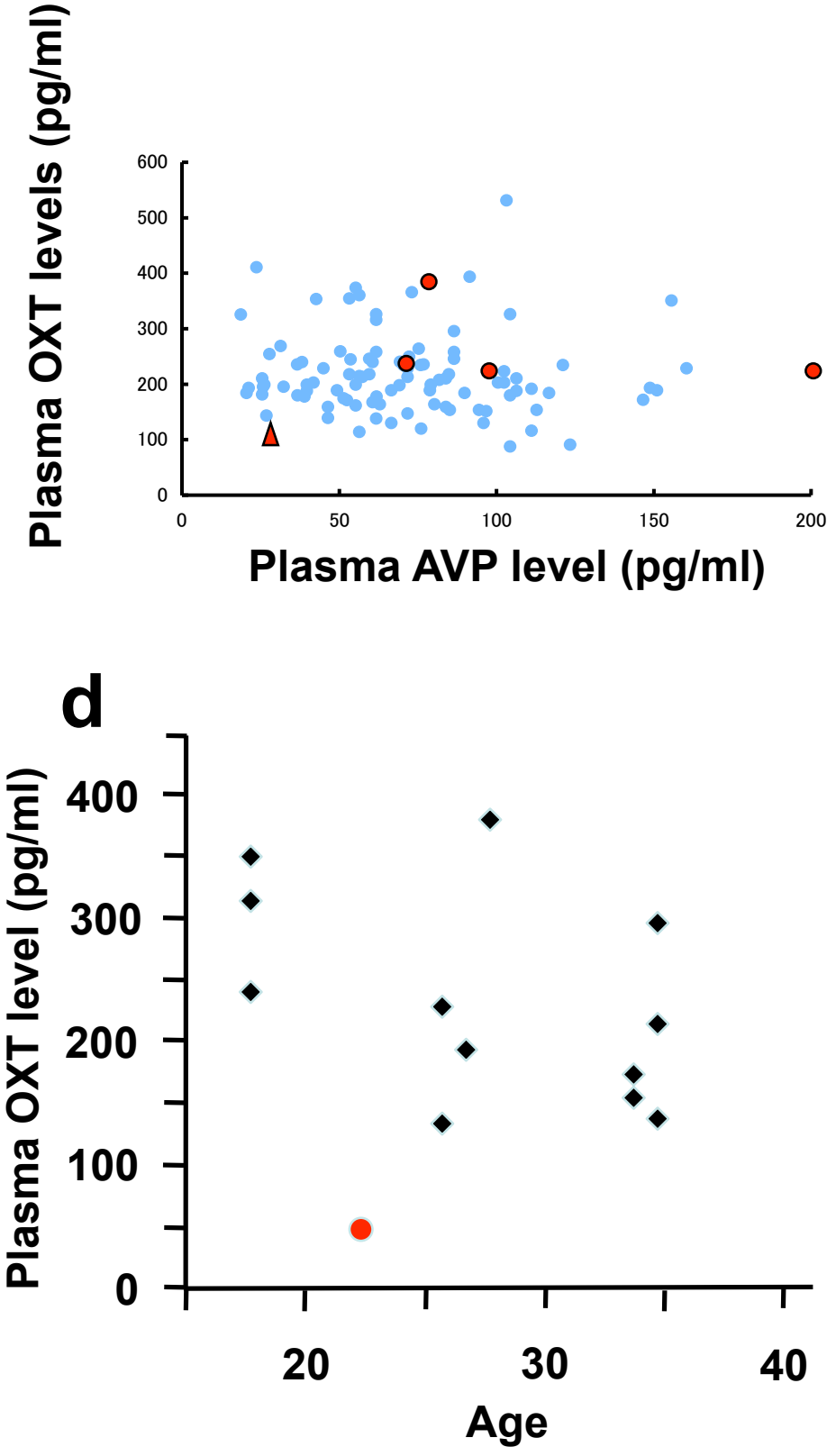

b
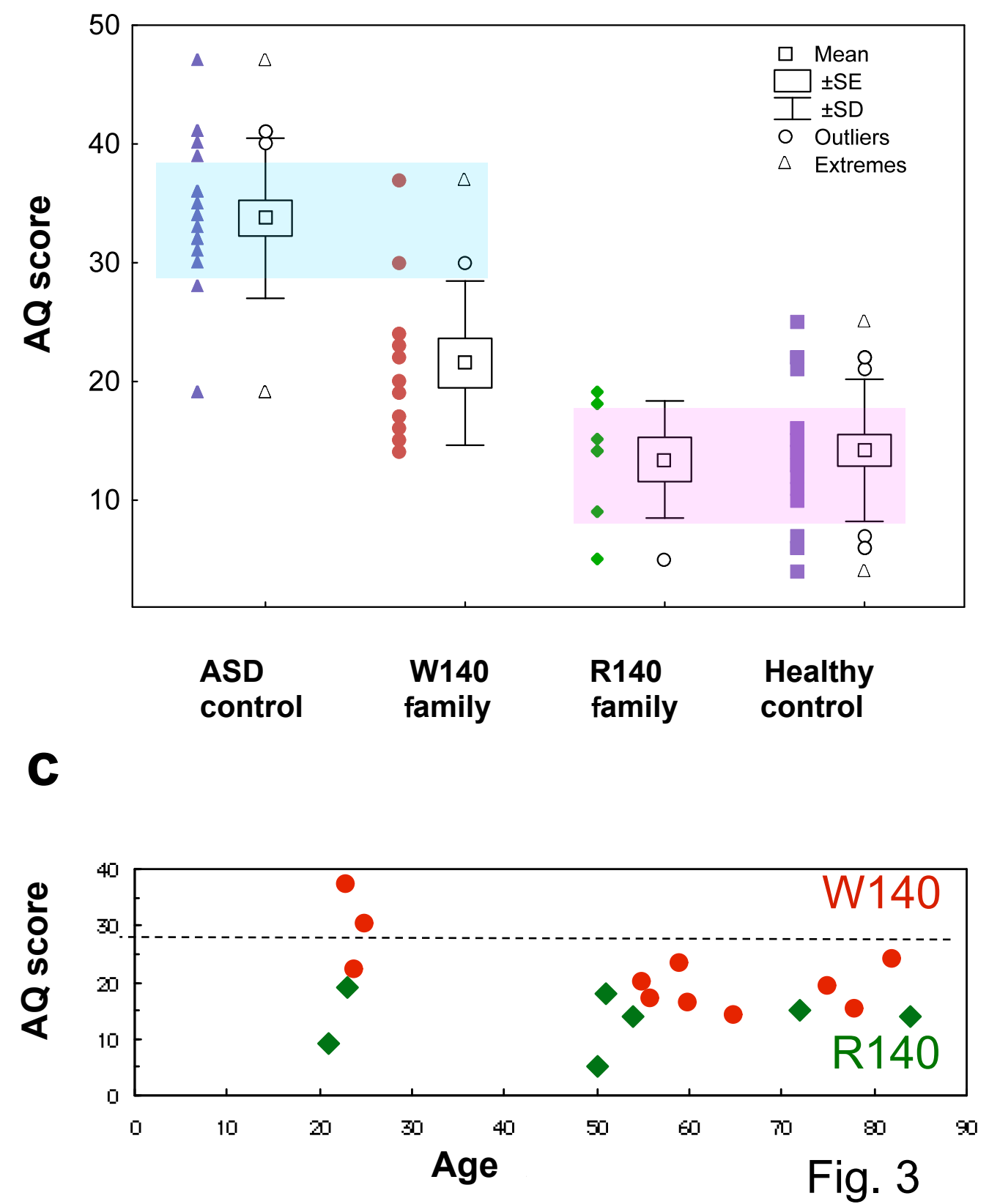

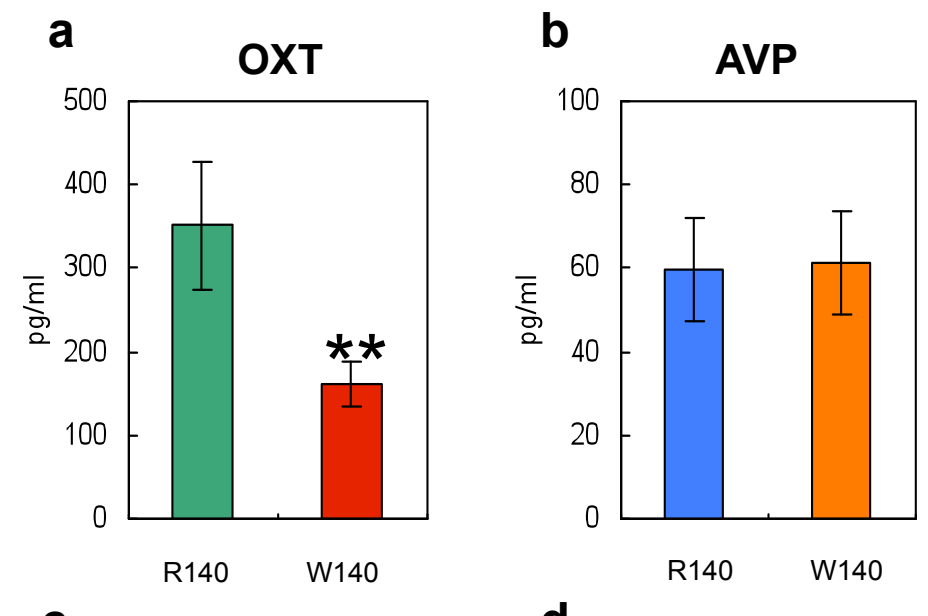

Fig. 4
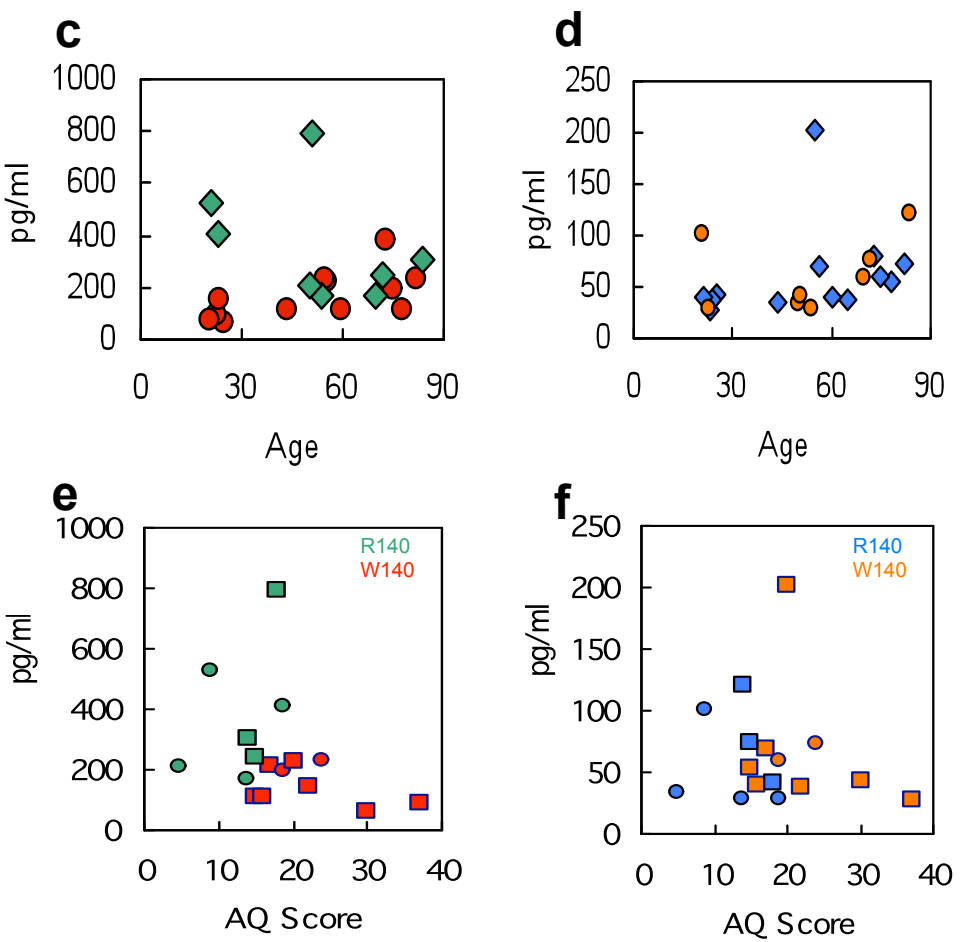


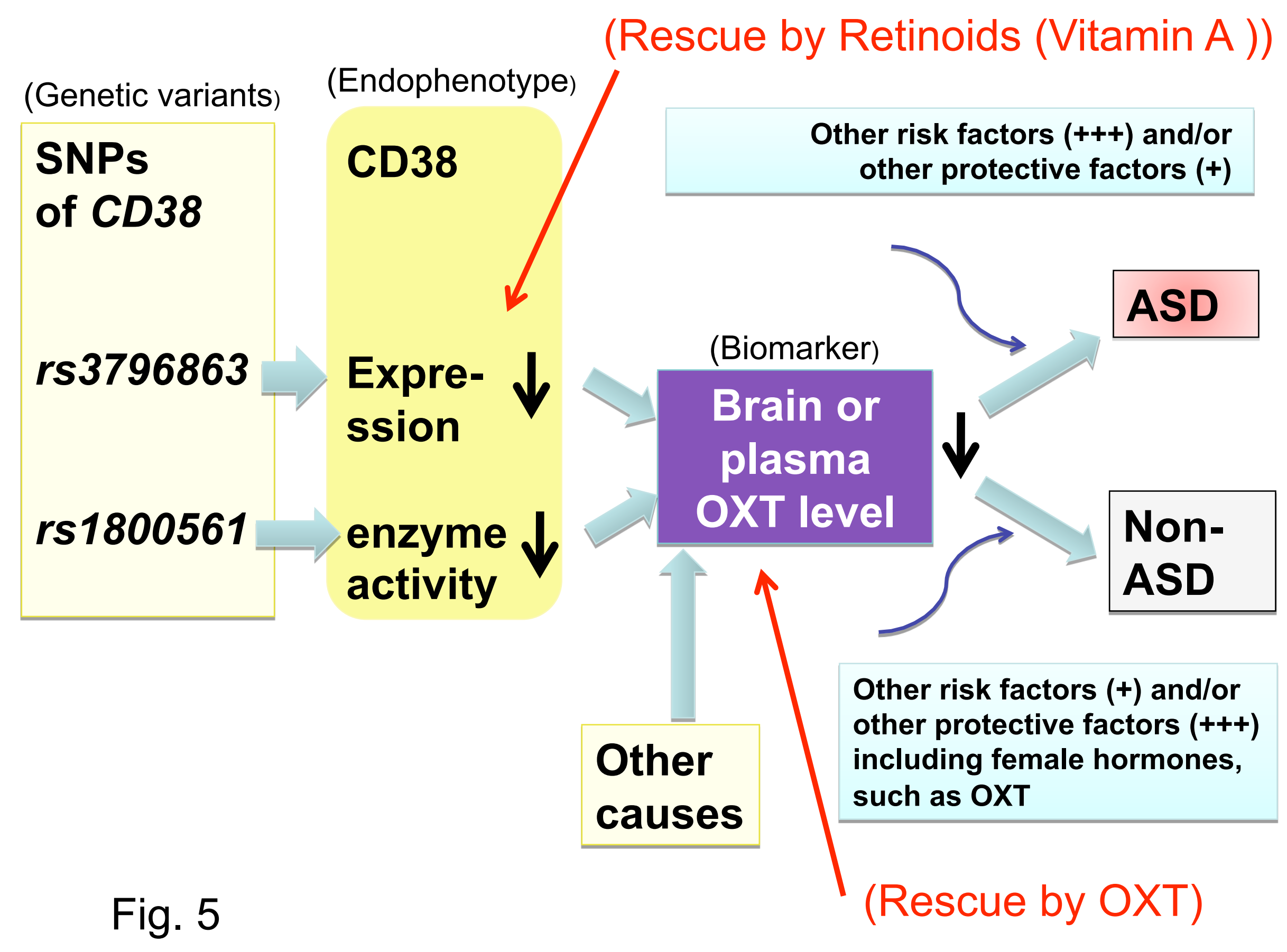

